\title{
Assessing controls of carbon and sulfur fluxes in high elevation floodplain sediments under transient hydrologic conditions
}

\author{
CHRISTIAN DEWEY ${ }^{* 1}$, PATRICIA FOX ${ }^{2}$, DIPANKAR \\ DWIVEDI $^{2}$, CAROLYN ANDERSON $^{3}$, HANNAH \\ NAUGHTON $^{1}$, MARCO KEILUWEIT ${ }^{3}$, SHAWN BENNER ${ }^{4}$, \\ PETER NICO $^{2}$, SCOTT FENDORF ${ }^{1}$
}

${ }^{1}$ Stanford University, 361 Panama Street, Stanford, CA 94305

${ }^{2}$ Lawrence Berkeley National Laboratory, 1 Cyclotron Road, Berkeley, CA 94720

${ }^{3}$ University of Massachusetts-Amherst, 161 Holdsworth Way, Amherst, MA 01003

${ }^{4}$ Boise State University, 1910 University Drive, Boise, ID 83725

*correspondence: cwdewey@stanford.edu

In the next century, mountain environments are expected to experience a drastic increase in average temperature and associated water dischard rates. Floodplain sediments can store large amounts of contaminants and nutrients, and thus understanding the response of near-surface biogeochemial floodplain processes to future climates is critical for predicting potential impacts on water quality. In this work, we use field observations and reactive transport modeling to understand the principal controls on fluxes of sulfur and carbon from floodplain sediments to the East River near Crested Butte, CO, USA (approx. $2700 \mathrm{mASL}$ ). We first quantify carbon and $\mathrm{S}$ fluxes from representative high and low permeability sediments under seasonally transient hydrologic conditions. We then assess the sensitivity of these fluxes to (i) variable permeability distributions and (ii) changes in the timing and magnitude of hydrologic transients. We find that carbon and sulfur fluxes are greatest along flowpaths in high permeability sediments adjacent to low permeability zones. Further, we find that carbon and sulfur fluxes increase as the duration and magnitude of peak river stage decreases and increases, respectively. These hydrologic conditions are expected with sudden warming and rapid snowmelt at higher elevations in the catchment. Our findings demonstrate the sensitivity of biogeochemical fluxes in floodplain sediments to sediment permeability and transient hydrologic conditions. Further, our findings reveal that a warmer future climate may increase carbon and sulfur fluxes from high-elevation floodplain sediments. This work thus contributes to predicting the impacts of changing climate on water quality. 